Estimation of oil spray cooling heat transfer coefficients on hairpin windings with reducedparameter models

Liu, C., Gerada, D., Xu, Z., Chong, Y.C., Michon, M., Goss, J., Li, J., Gerada, C., Zhang, $\mathrm{H}$.

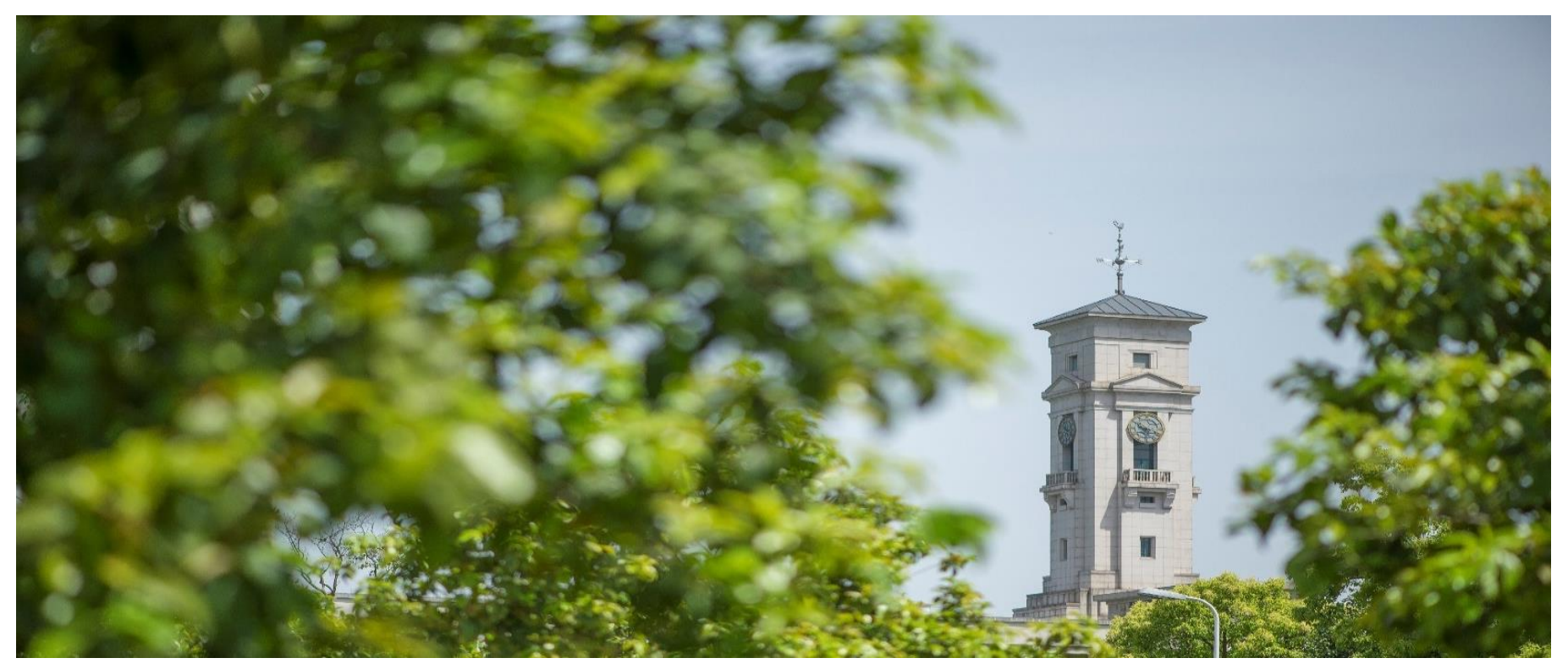


University of Nottingham Ningbo China, 199 Taikang East Road, Ningbo, 315100, Zhejiang, China.

First published 2020

This work is made available under the terms of the Creative Commons Attribution 4.0 International License:

http://creativecommons.org/licenses/by/4.0

The work is licenced to the University of Nottingham Ningbo China under the Global University Publication Licence:

https://www.nottingham.edu.cn/en/library/documents/research/global -university-publications-licence-2.0.pdf 


\title{
Estimation of Oil Spray Cooling Heat Transfer Coefficients on Hairpin Windings with Reduced-parameter Models
}

\author{
Chuan Liu, David Gerada, Senior Member, IEEE, Zeyuan Xu, Yew Chuan Chong, Melanie Michon, \\ James Goss, Member, IEEE, Jing Li, Member, IEEE, Chris Gerada, Senior Member, IEEE, and He \\ Zhang, Senior Member, IEEE
}

\begin{abstract}
Hairpin windings and spray cooling are becoming an increasingly popular combination in the field of high-performance electrical machine design. Machines adopting hairpin windings can achieve higher torque and power densities while enabling them to be manufactured automatically on a large scale to meet the rapid market growth of electric transport. Spray cooling is an effective way for high heat flux removal, which has shown great potentials in electrical machine applications. Although spray cooling has been studied for decades in different engineering applications, the focus had been on investigating its performance on regular surfaces using low-viscosity liquids, such as water. Additionally, many existing models for spray cooling heat transfer were built on spray parameters that are difficult to obtain without specialist equipment. Thus, most results from previous studies are difficult to be interpreted and directly applied to electrical machine applications. Practical and economical approaches for estimating the heat transfer coefficients of spray cooling on hairpin windings are needed. This paper proposes and validates an experimental approach based on reduced-parameter models which can be applied to predict the heat transfer coefficient of spray cooling setups on hairpin windings.
\end{abstract}

Index Terms - cooling, spraying, electric machines

\section{INTRODUCTION}

$\mathrm{R}$ ECENT developments in transport electrification have increased the need for electrical machines with improved performance metrics $[1,2]$. Machines with higher power density and improved cost-performance are always crucial in road, waterborne, aeronautics and rail transport electrification according to the European Commission [3]. The United States Department of Energy (DoE) has also established a series of goals to achieve a power density target of $33 \mathrm{~kW} / \mathrm{L}$ and a cost target of $\$ 6 / \mathrm{kW}$ for a $100 \mathrm{~kW}$ electric traction drive system by 2025 [4]. To achieve such goals, one of the main trends, especially in the electrification of road transport is to use electrical machines with directly-cooled hairpin windings. Key

Manuscript received April 6, 2020; revised July 6, 2020 and September 4, 2020; accepted October 5, 2020. This work was supported in part by Motor Design, Ltd., and the Ningbo S\&T projects under Grant 2018B10002, 2018B10001 and 2018B10082.

Chuan Liu (chuan.liu@nottingham.edu.cn), Jing Li (jing.li@nottingham .edu.cn), Chris Gerada (chris.gerada@nottingham.edu.cn and He Zhang (corresponding author, he.zhang@nottingham.edu.cn) are with the Key companies in the automotive industry have adopted this combination including General Motors, Toyota, Honda, and BorgWarner [5-7]. Hairpin-winding technologies, characterized by the use of rectangular conductors in the slot, can effectively achieve higher slot fill factors, with consequently lower DC copper losses amount and higher power densities [8-10]. The regular geometry of hairpin windings can also contribute to heat dissipation when combined with direct oil cooling, where oil is in direct contact with the windings and can flow through the gaps between the hairpins. Although such combinations show great potential in benefiting the performance-metrics of the machine, there is only a relatively small amount of literature that has been published regarding this topic. Wearing et al. [11] designed and manufactured a frameless permanent magnet motor with hairpin windings cooled by oil which was sprayed from the rotor shaft, however, the estimation procedure of the cooling performance is not reported. Park and Kim [12] numerically simulated the cooling phenomenon of a similar setup where the cooling oil was sprayed onto the end-windings from the rotor shaft, and the results were validated with experiments. Such cooling setup often requires dynamic sealing to transfer the oil from a stationary supply to the rotating shaft, which brings extra complexity to the design. El-Refaie et al. [13] developed a motor for traction applications and compared three cooling designs including (i)stator cooling jacket with microchannels, (ii)cooling tubes inside slots and (iii)end-winding spray cooling. The authors concluded that the spray cooling arrangement was the most effective and relatively simple in terms of design complexity. However, the key performance parameters such as HTC (heat transfer coefficient) are not reported.

Spray cooling has been studied for a long time in various engineering disciplines, mainly for its extraordinary merits in high heat flux removal [14]. There have been significant studies carried out in the last few decades focusing on developing models for spray cooling under various operating conditions.

Laboratory of More Electric Aircraft Technology of Zhejiang Province, University of Nottingham Ningbo China, Ningbo, China.

David Gerada (david.gerada@nottingham.ac.uk), Zeyuan Xu (Zeyuan.xu@, nottingham.ac.uk), Chris Gerada and He Zhang are with the Power Electronics, Machines and Control Group, University of Nottingham, Nottingham, UK

Yew Chuan Chong (Eddie.Chong@motor-design.com), Melanie Michon (Melanie.Michon@motor-design.com) and James Goss (james.goss@motordesign.com) are with Motor Design, Ltd., Wrexham, UK. 
Rybicki and Mudawar [15] developed a correlation between the Nusselt number $(\mathrm{Nu})$, the Reynolds number ( $\mathrm{Re})$, and the Prandtl number (Pr) for single-phase spray cooling regime based on the mean volumetric flux of the spray together with the Sauter mean diameter of the droplets. Karwa, Kale and Subbarao [16] proposed a simpler correlation between ' $\mathrm{Nu}$ ' and 'Re' based on water spray. More such correlations can be found in [17-22]. Most of these studies have proposed correlations based on dimensionless numbers which have forms similar to:

$$
\mathrm{Nu}=a \operatorname{Re}^{b} \operatorname{Pr}^{c}
$$

where $a, b$ and $c$ are empirical constants. Usually, these correlations are established within a wide range of parameters, which makes them applicable to different types of nozzles, types of liquid and operating conditions. However, when trying to apply these correlations for spray cooled electrical machines, researchers/engineers often face a number of challenges.

Firstly, most of the aforementioned correlations require knowledge of mean droplet diameters to serve as characteristic lengths, which usually can only be measured with technologies like phase-Doppler anemometry or high-speed photography combined with laser illumination [23]. Such techniques often require significant investment of funding, time, and personnel, which may not be readily available in most electrical machine research laboratories.

Secondly, the calculation of these dimensionless numbers often requires the knowledge of the coolant's properties under certain temperatures, such as thermal conductivity, specific heat capacity, viscosity, etc. These properties may not be provided by the fluid manufacturers, and measuring such properties often requires special equipment as well. A further issue is that most of these correlations are validated within specific ranges of parameters using lower-viscosity liquids. As a result, one cannot assume the fitness of these existing correlations if highviscosity liquids, for example engine oil, or transmission fluid, are used as the actual operating parameters are quite likely to deviate from the validated range of these correlations. Using different nozzles and inlet pressures may also further complicate the issue.

From the foregoing discussion, thus far, there is not any established, validated, readily applicable method for predicting the oil-spray cooling performance in electrical machines with hairpin windings. This paper attempts to provide a practical and economical approach that can be easily used within most typical electrical machine research environments to achieve the aforesaid goals. This paper is organized as follows: Section II establishes a reduced-parameter model for estimating the HTC of spray cooling and explains its use with hairpin windings. Section III presents the experimental process of determining the constants in the reduced-parameter model. An existing stator with hairpin windings is used in Section IV to validate the proposed model with determined constants. Finally, Section V summarizes the findings of this research.

\section{Establishing THE ReduCED-PARAMETER MODELS}

When designing the cooling system of an electrical machine, the type of coolant, inlet temperature, flow rate and system pressure are often predetermined by the application, which omits the need to formulate a general correlation for fluids other than the required one, or for flow rates/system pressures outside the permitted range. Hence a conveniently reduced-parameter model can be produced from conventional models as follows.

With definitions of the dimensionless numbers, (1) can be rewritten as:

$$
h L_{\mathrm{c}} / k=a\left(u_{\mathrm{c}} L_{\mathrm{c}} / v\right)^{b}\left(c_{\mathrm{p}} \mu / k\right)^{c}
$$

where $h$ is the HTC with a unit of $\mathrm{W} /\left(\mathrm{m}^{2} \mathrm{~K}\right), L_{\mathrm{c}}$ is the characteristic length with a unit of $\mathrm{m}, u_{\mathrm{c}}$ is the characteristic velocity with a unit of $\mathrm{m} / \mathrm{s}, v$ is the liquid's kinematic viscosity, $c_{\mathrm{p}}$ is its specific heat capacity, $\mu$ is its dynamic viscosity while $k$ is its thermal conductivity. In this study, the properties of the coolant are considered as constant since the same type of oil is used for all spray cooling experiments with constant inlet temperature. Therefore, the thermal conductivity, density, viscosity and specific heat capacity of the coolant in (2) can be omitted, and (2) is simplified to:

$$
h=a u_{\mathrm{c}}^{b} L_{\mathrm{c}}^{b-1}
$$

It should be noted that the constants in (3) are not the same as those in (2), and (3) only applies to a specific type of liquid at a constant temperature. There are multiple ways to define characteristic velocities and lengths. For characteristic velocity, both the mean droplet velocity and the mean volumetric flux are often used $[15,17,18]$.

The mean droplet velocity appears to be a preferable way since it is a velocity, which adheres to the definition of Reynolds number. However, the mean droplet velocity can be difficult to measure in real applications, as discussed in the previous section.

The mean volumetric flux is defined as the spray's effective volumetric flow rate, which is the flow rate of the coolant that lands on the impingement surface divided by the area of the impingement surface [18]. This quantity is easier to calculate since it only requires some basic operational parameters that can be conveniently measured with basic equipment, and it has the same dimensions as velocity $\left(\mathrm{LT}^{-1}\right)$. In this study, the mean volumetric flux is deemed as a preferable way to represent the characteristic velocity. Therefore (3) becomes:

$$
h=a \ddot{V}^{b} L_{\mathrm{c}}^{b-1}
$$

where $\ddot{V}$ is the mean volumetric flux. From literature [15-22], the characteristic length in (4) can often be defined as (i)a length scale related to the dimensions of the impingement surface, such as diameter, length and the square root of the surface area, (ii)the film thickness on the impingement surface or (iii)the mean droplet diameter. Since the diameter of the impingement surface is included in the calculation of the mean volumetric flux, and the film thickness on irregular surfaces, for example the end-windings' surface, is difficult to measure, the mean droplet diameter seems to be a better way for defining the characteristic length.

Due to the random nature of the atomization process, the diameters of the droplets generated varies in size [21]. In order to characterize the droplet diameters more conveniently, the 
Sauter mean diameter (SMD or $d_{32}$ ) is often used in the analysis. It is defined as the diameter of a droplet whose volume-tosurface area ratio is the same as that for the entire spray sample [14], which can be calculated by:

$$
d_{32}=\frac{\sum_{i} n_{i} d_{i}^{3}}{\sum_{i} n_{i} d_{i}^{2}}
$$

where $n_{i}$ is the number of droplets that shares a diameter of $d_{i}$.

As with the case of droplet velocity, the measurement of droplet diameters requires specialist techniques like laserDoppler anemometry or particle image velocimetry. Several analytical and empirical correlations have been developed in the past by a number of researchers, for example, by Couto et al. [24], Estes and Mudawar [21], to estimate droplet diameters without the need to conduct complicated experiments. However, most of these correlations are either only applicable for specific types of nozzles or require the precise knowledge of the nozzle's internal structural dimensions and coolant's physical properties, both of which may not be conveniently revealed by the suppliers or measured without special equipment. Nevertheless, the problem can be simplified, considering the scope of this study. The theoretical formulation for SMDs of pressure-swirl nozzles proposed by Couto et al. [24] can be written as:

$$
\begin{aligned}
& d_{32}=0.041\left(\pi^{2} \dot{m}^{2} \sigma^{2} \cos ^{4} \theta \rho_{\mathrm{L}}^{2}(1-x)^{2} \Delta p_{\mathrm{L}}^{-3} \rho_{\mathrm{a}}^{-1}\right)^{\frac{1}{6}} \\
& \quad\left(1+0.04 \mu_{\mathrm{L}} \Delta p_{\mathrm{L}}\left(\pi \dot{m} \rho_{\mathrm{a}}^{4}(1-x) \cos ^{-7}(\theta) \sigma^{-5} \rho_{\mathrm{L}}^{-5}\right)^{\frac{1}{3}}\right)^{0.2}
\end{aligned}
$$

where $\dot{m}$ is the mass flow rate, $\sigma$ is the surface tension of the liquid, $\theta$ is the spray cone half-angle, $\rho_{\mathrm{L}}$ is the density of the liquid, $\Delta p_{\mathrm{L}}$ is the nozzle pressure differential, $\rho_{\mathrm{a}}$ is the density of the air, and $x$ is the ratio between the air core area and the discharge orifice area of the nozzle, which can be calculated by:

$$
x=\sin ^{2} \theta /\left(1+\cos ^{2} \theta\right)
$$

For a specific nozzle that is spraying a specific type of liquid into the atmosphere at constant temperature, the surface tension of the fluid, together with the densities of the liquid and the air can be considered as constants [25]. In such cases, the mass flow rate of the liquid and the spray cone half-angle solely depend on the nozzle pressure differential. Therefore, the only independent variable in (6) and (7) remains to be the nozzle pressure differential, which is equal to the gauge pressure at the nozzle's inlet, namely $p_{\text {in }}$, if the nozzle sprays into the atmosphere. Thus, it can be concluded that the droplet diameter solely depends on the inlet pressure of the nozzle as long as the other parameters remain constant in the process. This conclusion enables designers to use the nozzle inlet pressure to serve as the characteristic length, and (4) becomes:

$$
h=a \ddot{V}^{b} p_{\text {in }}^{c}
$$

From the foregoing discussions, hence, the form of the reduced-parameter model for spray cooling HTC is established. Compared to the correlations in previous literature, (8) is considerably simpler, which enables the parameters to be determined with a simple experimental setup which only needs to measure the HTC while varying the mean volumetric flux and the inlet pressure of the nozzle. The determination of the mean volumetric flux is explained below.

For a circular impingement surface, as shown in Fig. 1, the mean volumetric flux of the liquid can be calculated based on the model developed by Mudawar and Estes [22] as:

$$
\ddot{V}=\frac{\dot{V}_{\mathrm{e}}}{A_{\mathrm{i}}}=\frac{\dot{V}}{A_{\mathrm{i}}} \cdot \frac{\left(1-\left(1+r_{\mathrm{i}}^{2} / D^{2}\right)^{-0.5}\right)}{1-\cos (\alpha / 2)}
$$

where $\dot{V}_{\mathrm{e}}$ is the effective volumetric flow rate, $A_{\mathrm{i}}$ is the area of the impingement surface, which is represented by the red circle in the figure, $\dot{V}$ is the total flow rate that discharges from the nozzle, $r_{\mathrm{i}}$ is the radius of the impingement surface, $D$ is the nozzle height, which is equal to the distance between the nozzle orifice and the impingement surface, while $\alpha$ is the spray angle. Equation (9) is based on the assumption that the volumetric flux along any spherical surface that is centered at the nozzle outlet is the same, which has also been validated for full-cone nozzles by Mudawar and Estes [22].

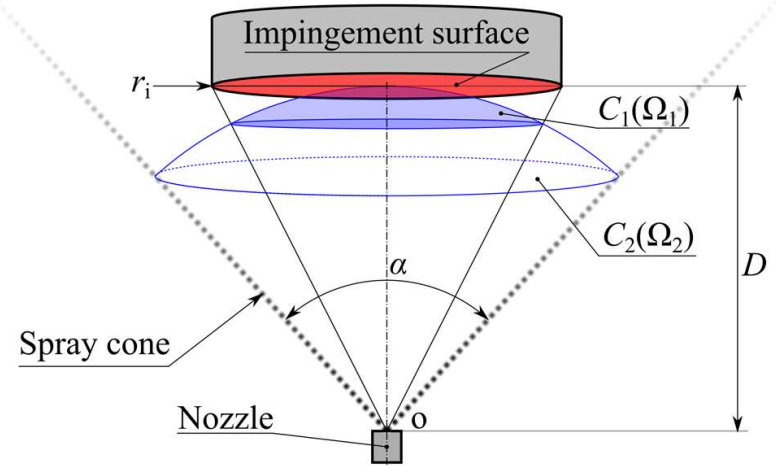

Fig. 1. The dimensions related to the determination of the amount of oil sprayed onto the impingement surface.

With trigonometric manipulations, equation (9) can be transformed into:

$$
\ddot{V}=\frac{\dot{V}}{A_{\mathrm{i}}} \cdot \frac{2 \pi D^{2}\left(1-\left(1+r_{\mathrm{i}}^{2} / D^{2}\right)^{-0.5}\right)}{2 \pi D^{2}(1-\cos (\alpha / 2))}=\frac{\dot{V}}{A_{\mathrm{i}}} \cdot \frac{C_{1}}{C_{2}}
$$

where $C_{1}$ and $C_{2}$ are the areas of the spherical caps shown in Fig. 1. Equation (10) can then be further transformed into:

$$
\ddot{V}=\frac{\dot{V}}{A_{\mathrm{i}}} \cdot \frac{C_{1} D^{-2}}{C_{2} D^{-2}}=\frac{\dot{V}}{A_{\mathrm{i}}} \cdot \frac{\Omega_{1}}{\Omega_{2}}
$$

where $\Omega_{1}$ and $\Omega_{2}$ are the solid angles subtended onto the nozzle orifice by the impingement surface and the spray cone as shown in Fig. 1 [26]. Equation (11) can be used to calculate the mean volumetric flux on any object as long as the object's solid angle and surface area can be determined.

By way of example, consider the case where the end region of a stator with hairpin windings is being sprayed on from the axial direction as shown in Fig. 2 ; in such case $\Omega_{1}$ is subtended by the portion of the end-winding's axial projection that is 
covered by the spray region, indicated by the area shaded in dark blue. To simplify the problem, this portion of the endwinding's projection can be transformed into a rectangle, indicated by the red rectangle in the same figure. The rectangle has a width equal to that of the end-winding and a length which is equal to the diameter of the spray region, which can be calculated by:

$$
l=2 r_{\mathrm{s}}=2 D \tan (\alpha / 2)
$$

where $l$ is the length of the rectangle and $r_{\mathrm{s}}$ is the radius of the spray region. The solid angle subtended by the rectangle onto the nozzle orifice can be calculated by [27]:

$$
\Omega_{1}=4 \cos ^{-1}\left[\frac{2 D\left(4 D^{2}+w^{2}+l^{2}\right)}{\left(4 D^{2}+l^{2}\right)\left(4 D^{2}+w^{2}\right)}\right]^{0.5}
$$

where $w$ is the width of the rectangle, which is equal to the width of the end-winding. Equation (13) can then be used in (11) to determine the mean volumetric flux on the end-winding.

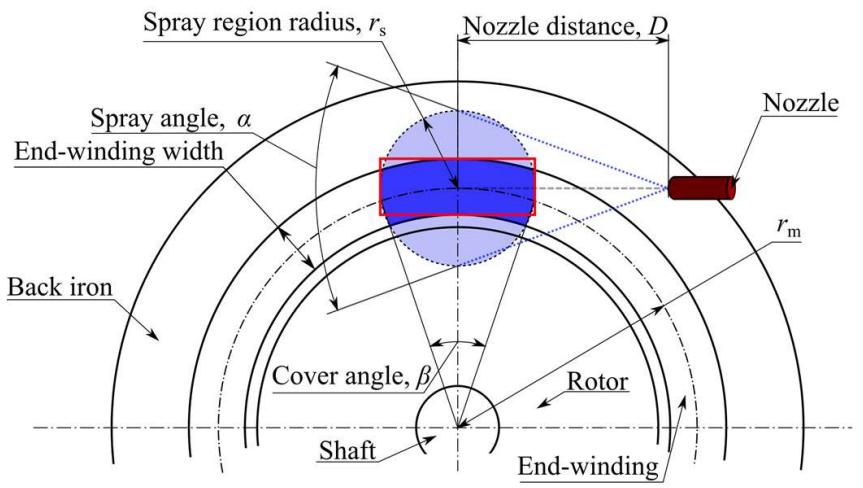

Fig. 2. Determining the mean volumetric flux in an axial-spray setup.

The cover angle $\beta$ can be calculated by [28]:

$$
\beta=2 \operatorname{acos}\left[\left(2 r_{\mathrm{m}}^{2}-D^{2} \tan ^{2}(\alpha / 2)\right) r_{\mathrm{m}}^{-2} / 2\right]
$$

where $r_{\mathrm{m}}$ is the mean radius of the end-winding (for the case in hand equal to $180.1 \mathrm{~mm}$ ) as shown in Fig. 2. Consequently, the impingement area can be calculated by:

$$
A_{\mathrm{i}}=N \beta A_{\mathrm{e}}
$$

where $N$ is the number of nozzles used in the cooling setup and $A_{\mathrm{e}}$ is the end-winding area, the determination of which will be discussed in Section III.

Alternatively, the oil spray can also be provided from the radial direction, as shown in Fig. 3. In this case, the calculations can be done in a similar manner. To facilitate the calculation, a cartesian coordinate system is built as shown in the same figure, with its origin, $\mathrm{O}$, lying on the nozzle outlet and its $\mathrm{x}$-axis pointing to the center of the stator, O'. The upper boundary of the spray cone (indicated by the dotted blue lines) intersects the outer diameter of the end-winding at point $\mathrm{A}\left(x_{1}, y_{1}\right)$.

It can be seen that in this case $\Omega_{1}$ is subtended onto the nozzle outlet by a rectangle that has a width equal to the end-winding height and a length equal to $2 y_{1}$, which is represented by the red line in Fig. 3. Therefore, $\Omega_{1}$ can be solved using (13) in a similar way once $y_{1}$ is determined.

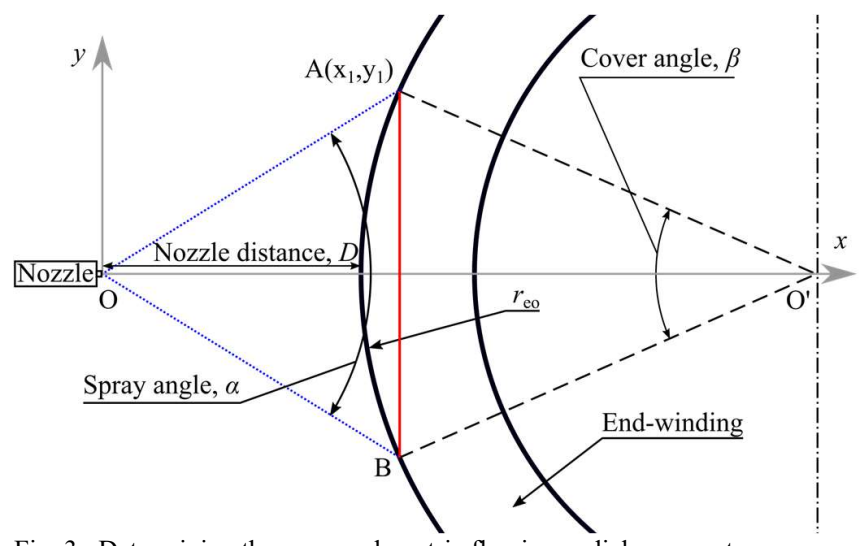

Fig. 3. Determining the mean volumetric flux in a radial-spray setup

The cover angle in this case can be found by solving the slope of AO'. Line OA can be expressed by:

$$
y=\tan (\alpha / 2) x
$$

The outer circle of the end-winding can be expressed by:

$$
\left(x-r_{\mathrm{eo}}-D\right)^{2}+y^{2}=r_{\mathrm{eo}}^{2}
$$

where $r_{\mathrm{eo}}$ is the outer surface radius of the end-winding (for the case in hand equal to $96.8 \mathrm{~mm}$ ) as shown in Fig. 3. With (16) and (17), $x_{1}$ and $y_{1}$ can be determined by solving:

$$
\left\{\begin{array}{l}
y_{1}=\tan (\alpha / 2) x_{1} \\
\left(x_{1}-r_{\mathrm{eo}}-D\right)^{2}+y_{1}^{2}=r_{\mathrm{eo}}^{2}
\end{array}\right.
$$

Once $x_{1}$ and $y_{1}$ are solved, $\beta$ can be calculated by:

$$
\beta=2 \operatorname{acos}\left(y_{1} / r_{\mathrm{eo}}\right)
$$

and $A_{\mathrm{i}}$ can subsequently be calculated with (15). Note that (15) is only valid for $N \beta \leq 2 \pi$. Otherwise, the spray regions of neighboring nozzles will intersect, and $A_{\mathrm{i}}$ is deemed to be the same as $A_{\mathrm{e}}$. Once $A_{\mathrm{i}}$ is determined, it can then be used in (11) to determine the mean volumetric flux on hairpin windings in order to apply the reduced parameter model.

\section{EXPERIMENTAL VALIDATION}

This section attempts to validate the proposed method through a series of experiments. First, the reduced-parameter model of HTC for two different hydraulic nozzles, hereafter referred to as nozzle A and nozzle B are established. Both these nozzles are full-cone pressure-swirl nozzles, but they have different spray angles, flow-rate capacities, and atomization capabilities. Details regarding the nozzles can be found in [28]. It should be noted that the proposed method does not apply to nozzles that cannot produce a full-cone spray, since these nozzles do not cover evenly the impingement surface, rendering the calculation of the mean volumetric flux meaningless. The constants in (8) are estimated by conducting practical tests 
under controlled conditions using a relatively simple and economical experimental setup. The resulting models can then be used to estimate the HTC of spray cooling designs on hairpin windings using the two proposed nozzles. In the final part of this section, another experimental setup with actual hairpin windings is used to measure the HTC of spray cooling, and the results from this are compared to the results estimated from the proposed reduced-parameter models to deduce some practical guidelines.

\section{A. Determination of the Reduced-parameter Models}

\section{1) Design of the Experimental Setup}

From the foregoing discussions, the experimental setup needs to be capable of varying (i)the nozzle pressure differential, as well as, (ii)the mean volumetric flux, in order to provide results for identifying the constants in (8). For a circular target, (8) can be rewritten as:

$$
h=a\left[\frac{\dot{V} \tan \left(\operatorname{atan}\left(r_{\mathrm{i}} / D\right) / 2\right)}{\pi r_{\mathrm{i}}^{2}\left(D^{2}+r_{\mathrm{i}}^{2}\right)^{0.5} \sin (\alpha / 2) \tan (\alpha / 4)}\right]^{b} p_{\mathrm{in}}^{c}
$$

From the above equation, it is apparent that the mean volumetric flux can be varied by changing the nozzle height while maintaining the impingement surface radius. On the other hand, the nozzle pressure differential can be adjusted by altering the nozzle inlet pressure if the downstream pressure is kept constant.

In light of this, an experimental setup is designed based on previous studies and established standards [18, 21, 29-31]. The test section of the setup is shown in Fig. 4, which consists of an inlet, a nozzle and a meter bar. The nozzle can be fixed at different heights, thus varying the mean volumetric flux. The oil flows in from the inlet, entering the nozzle through a tee connector, where a type- $\mathrm{K}$ thermocouple is fitted to measure the inlet temperature, and sprays onto the impingement surface of the meter bar, before exiting the test section.
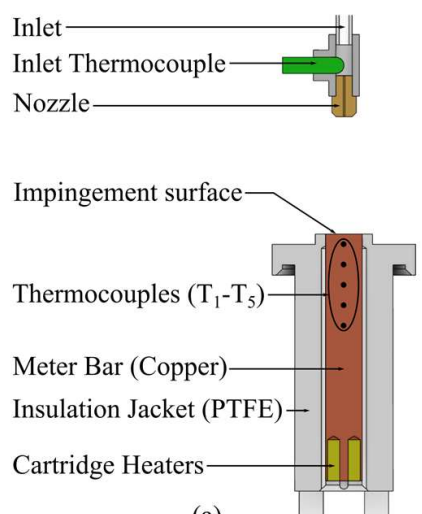

(a)

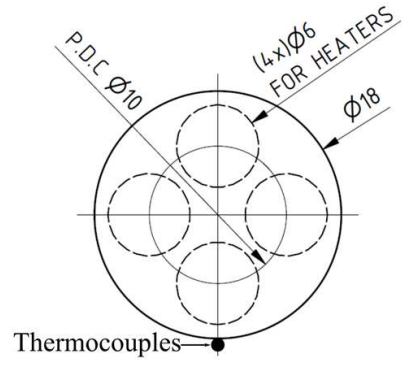

(b)

Fig. 4. The test section of the spray cooling experiment. (a) Cross-sectional view; (b) Top view, magnified, meter bar only.

The meter bar is designed to be a precisely machined cylindrical copper bar which has five type-K thermocouples (numbered through T1 to T5) mounted with a fixed distance in between. Four 12-Volt 25-Watt cartridge heaters are inserted into the bottom of the meter bar. During the experiment, the cartridge heaters are powered by a DC power supply, generating heat which flows through the meter bar before being removed by the oil spray via the impingement surface. The meter bar is inserted into an insulation jacket made from PTFE (Polytetrafluoroethylene), which reduces heat losses through the cylindrical surface of the meter bar.

During the experiment, a temperature gradient is induced within the meter bar in the axial direction, which is measured by the thermocouples. Since the dimensions and the thermal properties of the meter bar are known, the rate of the heat flow through the meter bar, $\dot{Q}$, can be calculated by:

$$
\dot{Q}=k_{\mathrm{Cu}} A_{\mathrm{i}} \Delta T / L
$$

where $k_{\mathrm{Cu}}$ is the thermal conductivity of copper, while $\Delta T$ and $L$ are the temperature difference and distance between two thermocouples, respectively. The impingement surface area $\left(A_{\mathrm{i}}\right)$ is the cross-sectional area of the meter bar. The mean surface temperature of the impingement surface, namely $T_{\mathrm{s}}$, can be derived from the temperature readings of the five thermocouples using linear regression. Once $\dot{Q}, T_{\mathrm{s}}$ and the inlet temperature $T_{\text {in }}$ are known, the HTC can be determined by:

$$
h=\dot{Q} /\left(A_{\mathrm{i}}\left(T_{\mathrm{s}}-T_{\mathrm{in}}\right)\right)
$$

In order to deliver oil to the test section with the required temperature and flow rate, a fluid system is designed, as shown in Fig. 5. The oil first comes out of the oil temperature unit, which regulates the temperature of the oil, then goes through an 8 -micron filter before entering the high-pressure pump. The high-pressure pump can boost the oil pressure supplied to the nozzle to enable proper atomization of the oil. A positive displacement flow rate sensor and a pressure sensor are attached to measure flow rate and pressure, following which the oil enters the test section and sprays onto the impingement surface. The oil is then removed by a scavenge pump located at the outlet of the test section. A bypass line is located after the highpressure pump to adjust the flow rate of the oil. The coolant used in this study is a synthetic lubricant, and its properties have been reported in [28].

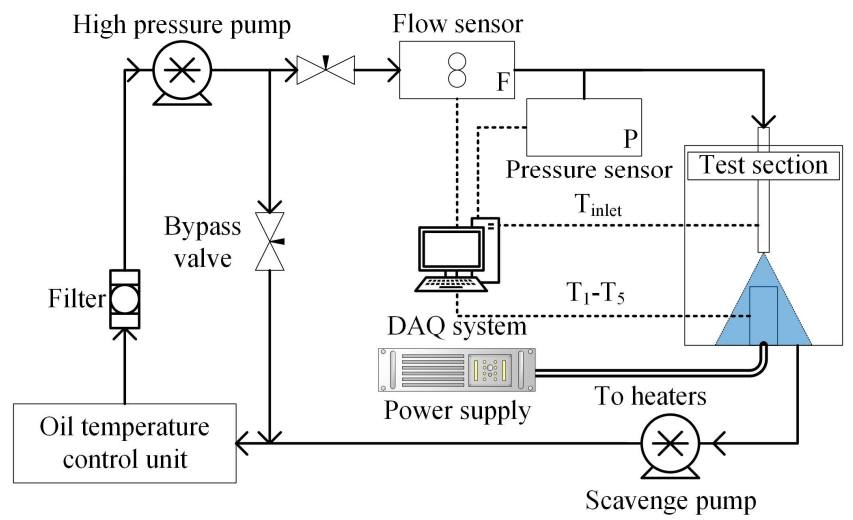

Fig. 5. Fluid system setup of the spray cooling test chamber.

All sensor and thermocouple readings are recorded by a data logger every 10 seconds, and the HTC is calculated based on (22). The results are averaged over 5-minute periods to reduce noise. The thermal equilibrium is determined when the change 
of HTC within 5 minutes is below $1 \%$. After this, the experiment is carried on for another 20 minutes to ascertain that the steady state has been reached. Based on the spray angles of the two nozzles and (9), the relationship between the nozzle height and the ratio of the effective to the total flow rate is determined and presented in Fig. 6. It can be seen from the results that when the nozzle height is below certain thresholds, the entire spray is caught by the impingement surface, achieving a ratio of 1 . However, under such circumstances, it is likely that the outer rim of the impingement surface is not subject to the direct impact of the oil spray and additional errors may occur. As a result, all experiments should be conducted with nozzle height above these thresholds in order to obtain reliable results.

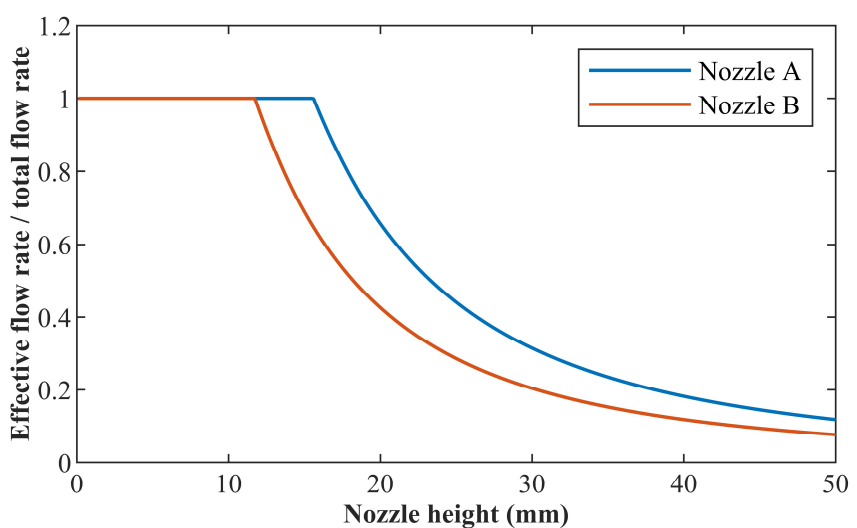

Fig. 6. Ratio of effective to total flow against nozzle height for the two considered nozzles.

\section{2) Experimental Results and Parameter Estimation}

A series of experiments are conducted with different inlet pressures and nozzle heights for both nozzle A and nozzle B. A nonlinear regression analysis is then carried out using commercial software to estimate the parameters using the experimental results. Regression models for the two nozzles are found to be:

$$
\begin{aligned}
& h_{\text {nozzle A }}=9930 \ddot{V}^{0.652} p_{\text {in }}^{0.192} \\
& h_{\text {nozzle B }}=562 \ddot{V}^{0.432} p_{\text {in }}^{0.310}
\end{aligned}
$$

The regression models and the experimental results are presented in Fig. 7 and Fig. 8. The colors of the surfaces correspond to the values of HTC. As can be deduced from these figures, the trends predicted by the models follow the experimental data quite well. As the inlet pressure is increased, the HTC increases. Furthermore, the HTC increases proportionally with the mean volumetric flux. However, as can be seen for some cases, there are some deviations (represented by the error bars), which may be due to the randomness of the spray distribution. The standard deviations for nozzle A and nozzle $\mathrm{B}$ are $635 \mathrm{~W} \cdot \mathrm{m}^{-2} \cdot \mathrm{K}^{-1}$ and $181 \mathrm{~W} \cdot \mathrm{m}^{-2} \cdot \mathrm{K}^{-1}$, respectively.

\section{B. Validation of the Reduced-parameter Models}

To validate the models described by (23) and (24), a bespoke experimental setup is developed on an existing automotive hairpin stator, as shown in Fig. 9. The stator has a 72-slot 2layer configuration. The stator inner diameter is $160 \mathrm{~mm}$, and its outer diameter is $215.3 \mathrm{~mm}$, while the stack length is $60 \mathrm{~mm}$. The dimensions of the hairpin wire are $3 \mathrm{~mm}$ by $4 \mathrm{~mm}$. The setup can provide oil spray onto the end region of the stator while measuring necessary parameters to determine the HTC of the spray cooling. Further details of the setup have been reported in [28]. Both nozzles considered in this research are tested with the axial-spray configuration with up to 12 nozzles, as shown in Fig. 9 (a), whereby the oil is sprayed onto the endwinding on the axial direction from the endcap. Additionally, nozzle A is also tested within a radial-spray configuration with three nozzles, as shown in Fig. 9 (b), whereby the oil is sprayed onto the end-winding radially from the left, right and top directions.

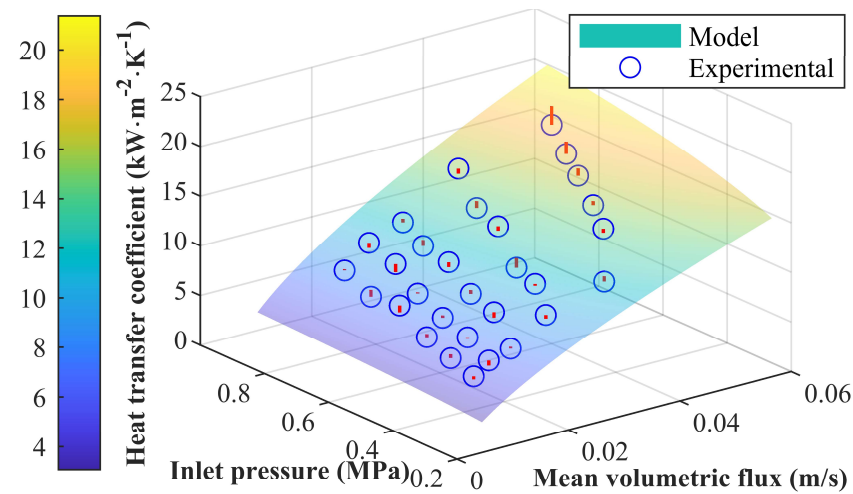

Fig. 7. Regression model and experimental results of nozzle A.

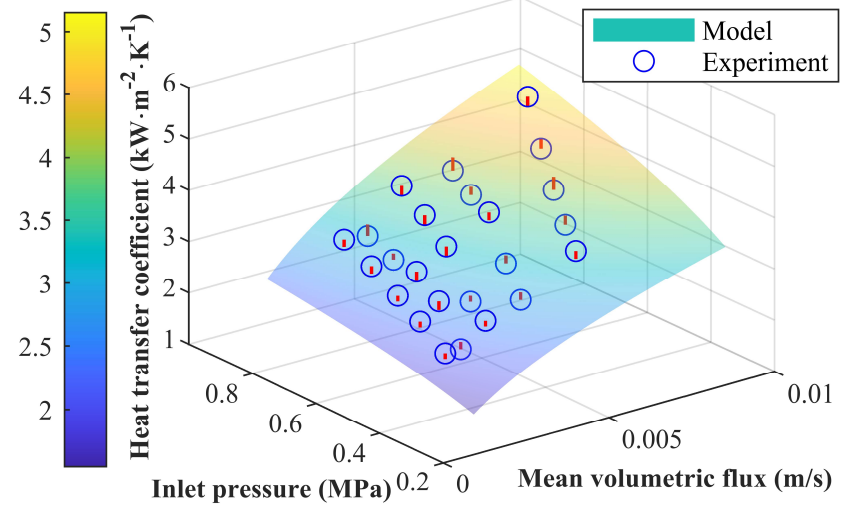

Fig. 8. Regression model and experimental results of nozzle B.

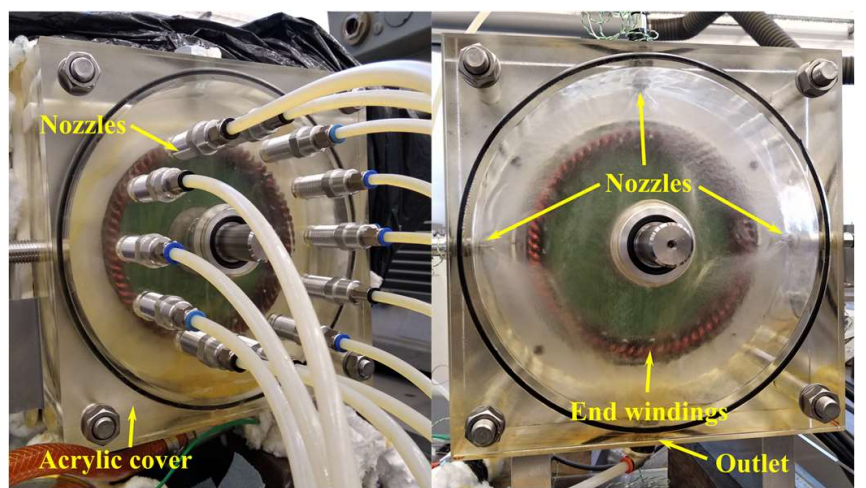

(a)

(b)

Fig. 9. Experimental setup for validating the proposed model. (a) Axial-spray setup; (b) Radial-spray setup. 
The HTCs in these experiments are calculated by:

$$
h=\dot{Q}_{\mathrm{s}} /\left(N \beta A_{\mathrm{e}}\left(T_{\mathrm{e}}-T_{\mathrm{in}}\right)\right)
$$

where $\dot{Q}_{\mathrm{s}}$ is the rate of heat flow dissipated by the oil spray, while $T_{\mathrm{e}}$ is the mean temperature of the end-winding measured by 24 thermocouples evenly mounted inside. The end-winding area ' $A_{\mathrm{e}}$ ' is a critical parameter, which can be calculated in multiple ways as subsequently discussed. The rate of heat flow dissipated by the oil spray is calculated by subtracting the heat flow rate leaking to the environment from the power injected to the windings by the power supply as described in more detail in [28].

As with other studies of heat-transfer on electrical machines, at a fundamental level the geometry of an end-winding can be simplified into a half-bagel model $[32,33]$ as shown in Fig. 10. The simplest way to determine $A_{\mathrm{e}}$ is to use the projection area of the end-winding (EP). For axial-spray setups, the axial projection of the end surface, which is indicated by the green surface in the figure, can be used since it is directly facing the spray, and it can be calculated by:

$$
A_{\mathrm{e}}=\pi\left(r_{\mathrm{eo}}-r_{\mathrm{ei}}\right)^{2}
$$

where $r_{\mathrm{ei}}$ is the inner surface radius of the end-winding (83.3 $\mathrm{mm}$ in this case). On the other hand, for radial-spray setups, the radial projection of the end-winding can be used:

$$
A_{\mathrm{e}}=2 \pi r_{\mathrm{eo}} H_{\mathrm{e}}
$$

where $H_{\mathrm{e}}$ is the height of the end-winding ( $25 \mathrm{~mm}$ in this case). This method (EP) gives the smallest end-winding area among all the options considered in this paper.

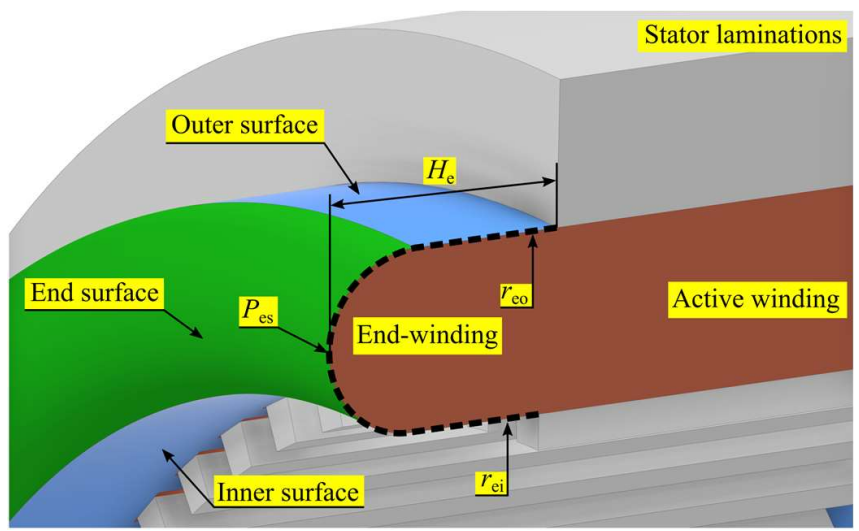

Fig. 10. A simplified model of the stator end region with related parts and dimensions marked out.

The second method to determine $A_{\mathrm{e}}$ is to use the actual area of the curved surface of the end-winding (ES). For axial-spray setups, this is the area of the end surface, while for radial-spray setups this is the sum of the outer surface area and part of the end-surface area that is subject to the spray. This approach gives a slightly larger contact area than the first method does.

The third method is to use the outer surface area of the entire end-winding (EE), which is the sum of the areas of the end surface, inner surface and outer surface as shown in Fig.10. It can be calculated by:

$$
A_{\mathrm{e}}=2 \pi r_{\mathrm{m}} P_{\mathrm{es}}
$$

where $P_{\mathrm{es}}$ is the perimeter of the end-winding cross-section, which is indicated by the dashed black line in Fig. 10. Both the second and the third methods require the knowledge of the contour of the end-winding geometry.

The fourth method considered in this paper to determine $A_{\mathrm{e}}$ is to calculate the area based on the surface area of individual wires (AS), which gives the maximum area amongst all the four methods discussed in this study. The most suitable definition of $A_{\mathrm{e}}$ is determined below based on experimental results.

A large number of experiments are carried out with the two nozzles under various oil flow rates, inlet pressures and numbers of nozzles. To investigate the difference between various methods for calculating the end-winding area, the HTCs are calculated with all the four aforementioned methods. The results are shown in Table I, where the percentage error between the experimental results (from (25)) and the results calculated from the proposed model (from (23) and (24)) are used to evaluate the feasibility of different approaches of defining $A_{\mathrm{e}}$. A positive error indicates the proposed models overestimate the experimental results and vice versa.

TABLE I

COMPARISON BETWEEN EXPERIMENTAL AND THEORETICAL RESULTS

\begin{tabular}{ccrrrr}
\hline \hline & & \multicolumn{4}{c}{ Average HTC } \\
Nozzle & Method & $\begin{array}{c}A_{\mathrm{e}} \\
\left(\mathrm{mm}^{2}\right)\end{array}$ & \multicolumn{2}{c}{$\left.\mathrm{W} \cdot \mathrm{m}^{-2} \cdot \mathrm{K}^{-1}\right)$} & Error \\
& & & Experiment & Model & \\
\hline & EP & 7,638 & 11,795 & 6,757 & $-42.7 \%$ \\
A & ES & 11,998 & 7,509 & 5,034 & $-33.0 \%$ \\
(axial) & EE & 35,928 & 2,507 & 2,463 & $-1.8 \%$ \\
& AS & 86,400 & 1,043 & 1,390 & $33.3 \%$ \\
\hline & EP & 15,205 & 7,301 & 6,113 & $-16.6 \%$ \\
A & ES & 17,100 & 6,492 & 5,662 & $-13.2 \%$ \\
(radial) & EE & 35,928 & 3,090 & 3,490 & $12.4 \%$ \\
& AS & 86,400 & 1,285 & 1,970 & $52.6 \%$ \\
\hline & EP & 7,638 & 5,661 & 2,964 & $-47.6 \%$ \\
B & ES & 11,998 & 3,604 & 2,439 & $-32.3 \%$ \\
(axial) & EE & 35,928 & 1,203 & 1,519 & $26.2 \%$ \\
& AS & 86,400 & 500 & 1,040 & $107.8 \%$ \\
\hline \hline
\end{tabular}

It is apparent that the results from the two nozzles behave differently to the change of $A_{\mathrm{e}}$. When using the end-winding projection area (EP) as $A_{\mathrm{e}}$, axial-spray setups yield a large underestimation of $42.7 \%$ and $47.6 \%$ for nozzle A and B, respectively. These values close in to around $33 \%$ when using the end-winding surface area (ES). However, the errors of the two nozzles begin to deviate from each other and eventually result in an overestimation of the HTC as the end-winding area increases further. On the other hand, the radial-spray setup using nozzle A yields smaller underestimations when calculated with the end-winding projection area (EP) and the end-winding surface area (ES). When using the entire end-winding area (EE) for the calculation, the axial-spray setups using nozzles A achieve a very small error, whereas the other two groups show overestimation. Finally, using the actual all-wire surface area 
(AS) causes overestimation for all setups.

From this study, using the end-winding surface area (ES) is deemed to be a more favorable approach, which yields underestimations of HTC for all three setups, providing appropriate safety margins for the thermal design of electrical machines, with the detailed results presented in Fig. 11 and Fig. 12. In Fig. 11, it can be seen that the proposed model achieves underestimation for all experimental result points, and the results from all three setups follow the model line well. On the other hand, the proposed model in Fig. 12 achieves underestimation for all experimental result points except for one point, and the agreement between the proposed model and the experimental results reduces as the number of nozzles decreases. The findings indicate that the accuracy of the model may be affected by both the type as well as the number of nozzles. Thus, appropriate cautions need to be taken in using the proposed method, especially when carrying out experiments with insufficient spray coverage of the end-windings, or when operating nozzles towards the lower-end of their inlet pressure requirement.

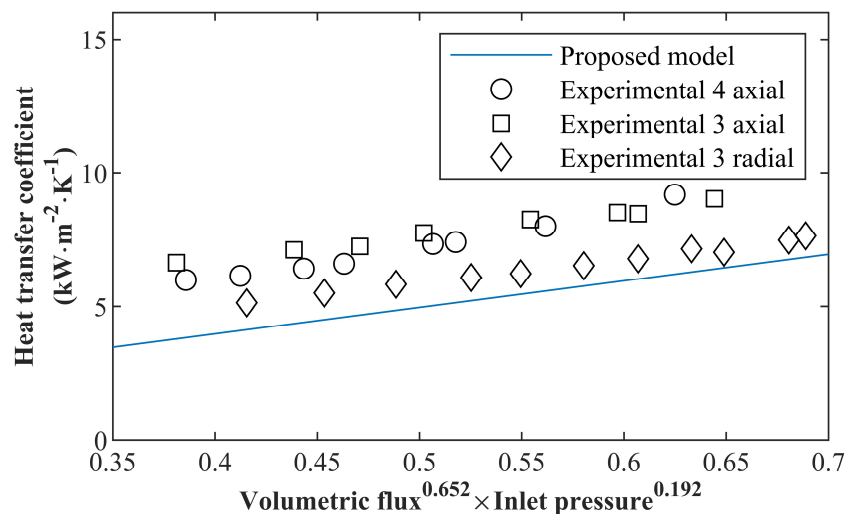

Fig. 11. Comparison between experimental and theoretical results for axialspray and radial-spray setups using various numbers of nozzle A.

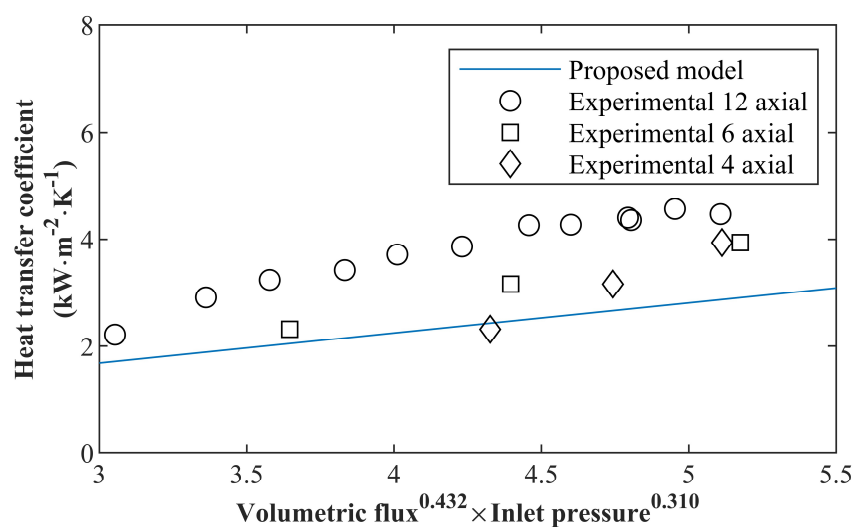

Fig. 12. Comparison between experimental and theoretical results for axialspray setups using various numbers of nozzle B.

It can be seen from the results that the proposed models can reflect the general trend of the experimental results. In particular, the overall trends expressed by the experimental results of nozzle A are in good agreement with the proposed model for all cases. In contrast, results from the type-B nozzle show larger discrepancies to the model, and such behaviors are different for the three setups with different numbers of nozzles.
The discrepancies on the general trend are observed to increase as the number of nozzles decreases. This suggests that the reduced-parameter model's ability to estimate the HTC of oil spray cooling designs may vary between different types and numbers of nozzles in use.

In addition, results in Fig. 11 suggest that the radial-spray setup may be less effective compared to the axial-spray setup for the type-A nozzle under similar operating conditions. The reason behind this phenomenon may be that in axial-spray setups, the oil spray landing outside of the end-winding surface tends to flow downward along the back-iron, which may intersect with the end-winding at some point and contribute to the total heat transfer in the process. On the other hand for radial-spray setups, part of the oil spray that is not caught by the end-winding eventually reaches the inner face of the endcap and flows down to the outlet without getting in contact with the endwinding. As a result, axial-spray setups tend to be slightly more effective compared to the radial-spray setups.

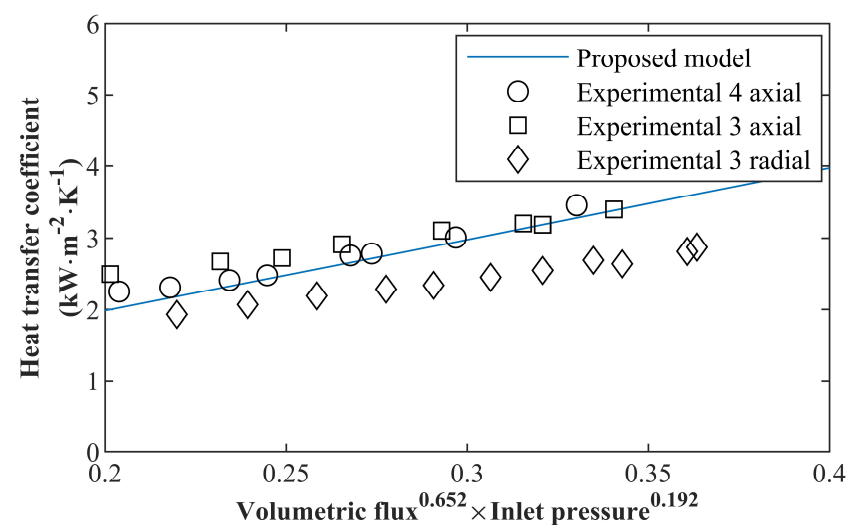

Fig. 13. Comparison between experimental and theoretical results for nozzle A with the contact area increased by a factor of 2.66 .

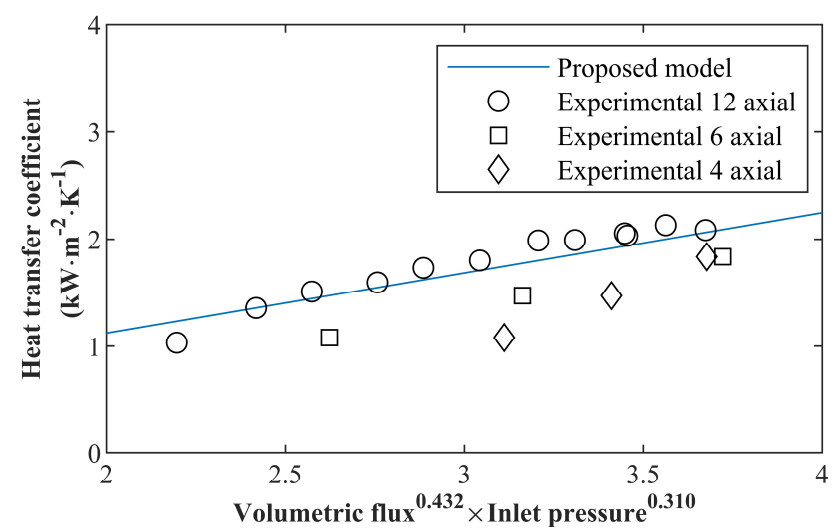

Fig. 14. Comparison between experimental and theoretical results for nozzle B with the contact area increased by a factor of 2.14

As shown in Table I, the accuracy of the model is greatly affected by the value of the contact area. Thus, it is possible to enhance the model accuracy by compensating for $A_{\mathrm{e}}$. It is found that increasing $A_{\mathrm{e}}$ by a factor of 2.66 and 2.14 for nozzle A and $\mathrm{B}$ can reduce the mean absolute percentage deviation of the models down to $12.6 \%$ and $12.3 \%$ respectively. The results are shown in Fig. 13 and Fig. 14. In particular, the axial-spray setups using nozzle A and the twelve-nozzle-B setup can be better described with the reduced-parameter model. Exact 
values of the area modification factor may be nozzle-typedependent. Further research is required to identify the nature of this factor.

\section{CONCLUSIONS}

The present study was undertaken to develop a practical and economical method for predicting HTCs of oil spray cooling arrangements on hairpin windings. The study has shown that in typical electrical-machine-design environments, reducedparameter models can be established based on specific design constraints, which enable the use of simple experimental setups to determine the constants in the model. These can then be used to estimate the cooling setup's performance on real electrical machine designs. The required calculation procedures for applying the model onto hairpin windings have also been described. The proposed method was validated using an existing stator with hairpin windings. Several approaches for calculating the end-winding area have been proposed and compared, among which a conservative way based on the curved surface area is proposed for providing safer estimations. Considering the complexities with spray cooling of hairpin motors, results for both nozzles shown agreement to the estimated values with reasonable deviations. It should be noted that in the use of the proposed method, readers should make use of appropriate judgement if their case-in-hand features markedly dissimilar characteristics to the case presented in this paper, for example if a very high layer number of pins is used, or for the case of small spray angles.

For future studies, the authors will attempt to investigate other factors, such as rotational effects, and their impact on the performance of spray cooling in electrical machines.

\section{REFERENCES}

[1] D. Gerada, A. Mebarki, N. L. Brown, C. Gerada, A. Cavagnino, and A. Boglietti, "High-Speed Electrical Machines: Technologies, Trends, and Developments," (in English), Ieee Transactions on Industrial Electronics, vol. 61, no. 6, pp. 2946-2959, Jun 2014.

[2] D. Gerada, Z. Xu, D. Golovanov, and C. Gerada, "Comparison of electrical machines for use with a high-horsepower marine engine turbocharger," in 2018 25th International Workshop on Electric Drives: Optimization in Control of Electric Drives (IWED), 2018, pp. 1-6.

[3] G. Meyer, "Electrification of the Transport System - Expert Group Report," EUROPEAN COMMISSION, Brussels, 2017, [Online]. Available: https://ec.europa.eu/programmes/horizon2020/en/news/electrificationtransport-system-expert-group-report-0.

[4] "Electrification FY2018 Annual Progress Report," U.S. Department of Energy, DOE/EE-1832, 2019, [Online]. Available: https://www.energy.gov/eere/vehicles/downloads/electrification-fy2018annual-progress-report, Accessed on: Oct 3rd, 2019.

[5] J. D. Kelly, "Chevrolet Bolt EV Traction Motor - Deep Dive," ed. United States: YouTube, 2018.

[6] J. D. Kelly, "4th Gen Prius, Prius Prime Transaxle - P610 Deep Dive (P710 Similar)," ed. United States: YouTube, 2017.

[7] (2019, Oct. 04). BorgWarner HVH series motors [Online]. Available: https://www.cascadiamotion.com/borgwarner-housed-motors.html.

[8] G. Berardi and N. Bianchi, "Design Guideline of an AC Hairpin Winding," in 2018 XIII International Conference on Electrical Machines (ICEM), 2018, pp. 2444-2450.

[9] N. Bianchi and G. Berardi, "Analytical Approach to Design Hairpin Windings in High Performance Electric Vehicle Motors," in 2018 IEEE Energy Conversion Congress and Exposition (ECCE), 2018, pp. 43984405.

[10]M. Popescu, J. Goss, D. A. Staton, D. Hawkins, Y. C. Chong, and A. Boglietti, "Electrical Vehicles_-Practical Solutions for Power Traction Motor Systems," Ieee TInd Appl, vol. 54, no. 3, pp. 2751-2762, 2018.
[11]A. D. Wearing, J. Haybittle, R. Bao, J. W. Baxter, C. Rouaud, and O. Taskin, "Development of High Power 48V Powertrain Components for Mild Hybrid Light Duty Vehicle Applications," in 2018 IEEE Energy Conversion Congress and Exposition (ECCE), 2018, pp. 3893-3900.

[12]M. H. Park and S. C. Kim, "Thermal characteristics and effects of oil spray cooling on in-wheel motors in electric vehicles," Applied Thermal Engineering, vol. 152, pp. 582-593, 2019.

[13]A. M. El-Refaie et al., "Advanced High-Power-Density Interior Permanent Magnet Motor for Traction Applications," Ieee T Ind Appl, vol. 50, no. 5, pp. 3235-3248, 2014.

[14]G. Liang and I. Mudawar, "Review of spray cooling - Part 1: Single-phase and nucleate boiling regimes, and critical heat flux," International Journal of Heat and Mass Transfer, vol. 115, pp. 1174-1205, 2017.

[15]J. R. Rybicki and I. Mudawar, "Single-phase and two-phase cooling characteristics of upward-facing and downward-facing sprays," (in English), International Journal of Heat and Mass Transfer, vol. 49, no. 12, pp. 5-16, Jan 2006.

[16]N. Karwa, S. R. Kale, and P. M. V. Subbarao, "Experimental study of nonboiling heat transfer from a horizontal surface by water sprays," (in English), Experimental Thermal and Fluid Science, vol. 32, no. 2, pp. 571579, Nov 2007.

[17]S. S. Hsieh and C. H. Tien, "R-134a spray dynamics and impingement cooling in the non-boiling regime," (in English), International Journal of Heat and Mass Transfer, vol. 50, no. 3-4, pp. 502-512, Feb 2007.

[18]I. Mudawar and W. S. Valentine, "Determination of the local quench curve for spray-cooled metallic surfaces," Journal of Heat Treating, journal article vol. 7, no. 2, pp. 107-121, September 011989.

[19]Y. J. Tao, X. L. Huai, L. Wang, and Z. X. Guo, "Experimental characterization of heat transfer in non-boiling spray cooling with two nozzles," (in English), Applied Thermal Engineering, vol. 31, no. 10, pp. 1790-1797, Jul 2011.

[20]S. J. Jiang and V. K. Dhir, "Spray cooling in a closed system with different fractions of non-condensibles in the environment," (in English), International Journal of Heat and Mass Transfer, vol. 47, no. 25, pp. 53915406, Dec 2004.

[21]K. A. Estes and I. Mudawar, "Correlation of Sauter Mean Diameter and Critical Heat-Flux for Spray Cooling of Small Surfaces," (in English), International Journal of Heat and Mass Transfer, vol. 38, no. 16, pp. 29852996, Nov 1995.

[22]I. Mudawar and K. A. Estes, "Optimizing and predicting CHF in spray cooling of a square surface," (in English), J Heat Trans-T Asme, vol. 118, no. 3, pp. 672-679, Aug 1996.

[23]T. D. Fansler and S. E. Parrish, "Spray measurement technology: a review," Measurement Science and Technology, vol. 26, no. 1, p. 012002, 2014/12/01 2014.

[24]H. S. Couto, J. A. Carvalho, and D. Bastos-Netto, "Theoretical Formulation for Sauter Mean Diameter of Pressure-Swirl Atomizers," (in English), Journal of Propulsion and Power, vol. 13, no. 5, pp. 691-696, Sep-Oct 1997.

[25]A. Gatenby. (2013, 4th, July). What are the Primary Conditions Affecting Surface Tension? [Online]. Available: https://www.cscscientific.com/cscscientific-blog/what-are-the-primary-conditions-affecting-surface-tension.

[26]T. Watkins. (Aug. 21). The Concept of Solid Angle [Online]. Available: http://www.sjsu.edu/faculty/watkins/solidangle.htm.

[27] R. J. Mathar, "Solid Angle of a Rectangular Plate," Max-Planck Institute of Astronomy, Heidelberg, Germany, 2019, [Online]. Available: http://www.mpia.de/ mathar/public/mathar20051002.pdf, Accessed on: Aug. 18, 2019.

[28]C. Liu et al., "Experimental Investigation on Oil Spray Cooling With Hairpin Windings," IEEE Transactions on Industrial Electronics, vol. 67, no. 9 , pp. 7343-7353, 2020.

[29] Standard Test Method for Thermal Transmission Properties of Thermally Conductive Electrical Insulation Materials, ASTM D5470-17, 2017.

[30]M. R. Guechi, P. Desevaux, and P. Baucour, "On the Numerical and Experimental Study of Spray Cooling," The Journal of Computational Multiphase Flows, vol. 5, no. 4, pp. 239-249, 2013.

[31]P. Zhang, L. Ruan, and G. Gu, "Design of experimental device used for heat transfer research of single-phase and two-phase spray cooling," in 2011 International Conference on Electrical Machines and Systems, 2011, pp. 1-3.

[32]P. H. Mellor, D. Roberts, and D. R. Turner, "Lumped parameter thermal model for electrical machines of TEFC design," IEE Proceedings B Electric Power Applications, vol. 138, no. 5, pp. 205-218, 1991. 
[33]A. Boglietti and A. Cavagnino, "Analysis of the Endwinding Cooling Effects in TEFC Induction Motors," Ieee T Ind Appl, vol. 43, no. 5, pp. 1214-1222, 2007.

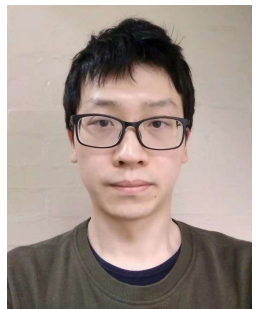

Chuan Liu received the B.E. degree in mechanical engineering from Nanjing Agricultural University, Nanjing, China, in 2015. He is currently working toward the Ph.D. degree in electrical and electronic engineering with the University of Nottingham Ningbo China, Ningbo, China. In 2015, he was a Research Assistant on Electrical Machine Design and Manufacture with the University of Nottingham Ningbo China.

$\mathrm{He}$ is currently working on innovative thermal management and mechanical design of high-performance electrical machines.

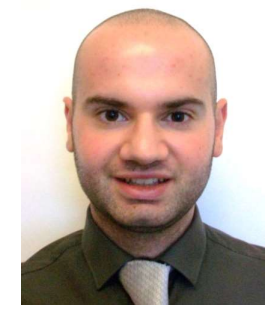

David Gerada (SM'20) received the Ph.D. degree in high-speed electrical machines from the University of Nottingham, Nottingham, U.K., in 2012.

From 2007 to 2016, he was with the R\&D Department, Cummins, Stamford, U.K., first as an Electromagnetic Design Engineer from 2007 to 2012, and then as a Senior Electromagnetic Design Engineer and Innovation Leader from 2012 to 2016. At Cummins, he pioneered the design and development of high-speed electrical machines, transforming a challenging technology into a reliable one suitable for the transportation market, while establishing industry-wide-used metrics for such machinery. In 2016, he joined the University of Nottingham where he is currently a Principal Research Fellow in Electrical Machines, responsible for developing state-of-the-art electrical machines for future transportation that push existing technology boundaries while propelling the new technologies to higher technology readiness levels.

Dr. Gerada is a Chartered Engineer in the UK and a member of the Institution of Engineering and Technology.

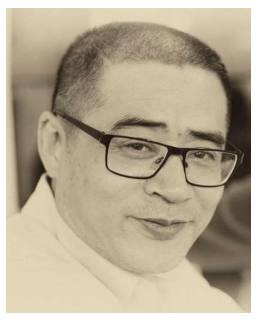

Zeyuan Xu received the Ph.D. degree in mechanical engineering from the University of Manchester, Manchester, U.K., in 2002.

He was a Research Fellow with the University of Manchester Institute of Science and Technology (UMIST), Brunel University, and the University of Nottingham, Nottingham, U.K. He is currently a Senior Research Fellow in Thermo Mechanical Design of High-Speed Electrical Machines within the Power Electronic, Machine and Control group, University of Nottingham. His main research interests include turbulent thermo-fluid flow, heat transfer enhancement, and thermal management of advanced electrical machines and power electronics.

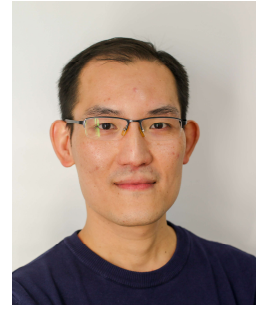

Yew Chuan Chong received the Ph.D. degree in electrical and electronic engineering from the University of Edinburgh, Edinburgh, U.K., under the Energy Technology Partnership's Energy Industrial Doctorate Program in 2015.

In January 2014, he joined Motor Design Ltd., Wrexham, U.K., as a Senior Research Engineer. In August 2018, he became a Lead Thermal Special of Motor Design Ltd in UK, leading thermal aspects of research/consultancy projects and Motor-CAD software development. In November 2019, he became the Technical Lead (Asia) of the MDL office in Shanghai, China, managing with both technical and commercial functions in the Chinese market.

His major research area is improving algorithms for thermofluid modelling in electrical machines, and effectively make use of lumped parameter thermal network, flow network, finite element and computational fluid dynamic (CFD) methods for thermal management of electrical machine and to improve the cooling of electrical machines. He has published more than 30 technical papers in conferences and peer-reviewed journals. His publications have received the best paper awards on Ecological Vehicles in the 2016 Eleventh International Conference on Ecological Vehicles and Renewable Energies (EVER) and Electrical Machines Committee Paper Award of IEEE Industry Application Society in 2017.

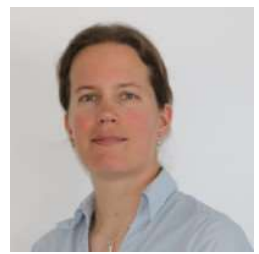

Melanie Michon received the Ph.D. degree in Electrical Engineering from the University of Sheffield, Sheffield, U.K.

She has 20 years of combined academic and industrial experience enabling her to provide thought leadership and to drive innovation with a clear focus on IP development and commercialisation. She joined MDL in April 2019 in the position of Head of Engineering, where she heads the engineering team and is responsible for delivering grant funded and large engineering projects, as well as technical presales support.

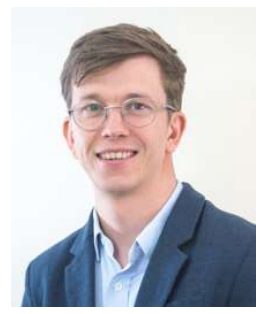

James Goss (M'15) received the M.Eng. degree in systems engineering from the University of Warwick, Coventry, U.K., in 2009, and the Engineering Doctorate in the design of brushless permanent magnet machines for automotive traction from the University of Bristol, Bristol, U.K., in 2014.

$\mathrm{He}$ is currently the CEO of Motor Design Ltd., where he mainly works on automotive $R \& D$ projects and software development with large industrial partners. 


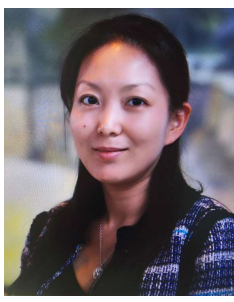

Jing Li (M'15) received the M.Sc. (Distinction) and B.Eng. (Hons.) degrees from the Beijing Institute of Technology, Beijing, China, and the Ph.D. degree from the University of Nottingham, Nottingham, U.K., in 2010, all in electrical and electronic engineering.

She was a Research Fellow after graduation within the Power Electronic, Machine and Control Group, University of Nottingham. In 2016, she as an Assistant Professor joined the University of Nottingham Ningbo China, Ningbo, China, where she is currently an Associate Professor with the Department of Electrical and Electronic Engineering. Her research interests include condition monitoring for motor drive systems and power distribution systems, advanced control, and design of motor drive systems.

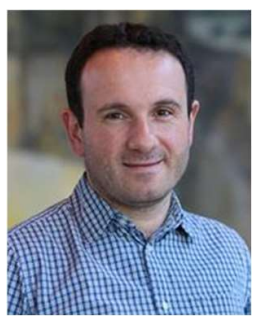

Chris Gerada (M'05-SM'12) received the Ph.D. degree in numerical modeling of electrical machines from the University of Nottingham, Nottingham, U.K., in 2005.

He was a Researcher with the University of Nottingham on high-performance electrical drives and on the design and modeling of electromagnetic actuators for aerospace applications. In 2008, he was appointed as a Lecturer in Electrical Machines; in 2011, as an Associate Professor; and in 2013, as a Professor with the University of Nottingham. He is currently an Associate Pro-Vice Chancellor for Industrial Strategy and Impact and Professor of Electrical Machines with the University of Nottingham. He has authored or coauthored more than 350 referred publications. His principal research interest includes electromagnetic energy conversion in electrical machines and drives, focusing mainly on transport electrification. He has secured over $£ 20 \mathrm{M}$ of funding through major industrial, European and U.K. grants.

Dr. Gerada was the Research Chair of the Royal Academy of Engineering in 2013 and also the Chair of the IEEE IES Electrical Machines Committee. He was an Associate Editor for the IEEE TRANSACTIONS ON INDUSTRY APPLICATIONS.

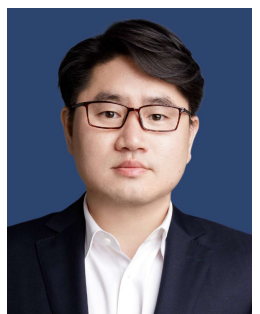

He Zhang (SM'18) received the B.Eng. degree from Zhejiang University, Hangzhou, China, in 2002, and the M.Sc. and $\mathrm{Ph} . \mathrm{D}$. degrees in electrical machines from the University of Nottingham, Nottingham, U.K., in 2004 and 2009, respectively.

He was a Research Fellow with the University of Nottingham and the Director with the BestMotion Technology Centre. He moved to the University of Nottingham Ningbo China, Ningbo, China, as a Senior Research Fellow in 2014 and as a Principal Research Fellow in 2016. He is currently the Director with the Nottingham Electrification Centre within the Power Electronics, Machines and Control Research Group, University of Nottingham. His research interests include high performance electric machines and drives for transport electrification. 